\section{À sombra das Forças Armadas}

Jorge ZAVERUCHA. FHC, Forças Armadas e policia: entre o autoritarismo e a democracia (19992002). Rio de Janeiro, Record, 2005. 285 páginas.

\section{Glenda Mezarobba}

Continuação de obra anterior que tratava, nas palavras do autor, da "frágil democracia" brasileira, o livro em análise tem como objeto central a relação entre democracia e controle civil sobre os militares. Nesse sentido, são três os seus objetivos principais:

a) discutir o paradoxo de certas cláusulas constitucionais terem sido escritas de acordo com os procedimentos democráticos, mas que resultaram, todavia, em conteúdos pouco liberais; b) mostrar que tais cláusulas constitucionais tornam impossível a consolidação de relações civis-militares democráticas; c) questionar os motivos da inexistência de tentativas regulares de mudança destas cláusulas constitucionais (p. 55).

Jorge Zaverucha não vê consolidação na democracia brasileira, nem a existência de Estado do Direito, preocupado que está com a grande distância entre a ordem legal formal e sua aplicação. Como não consegue pensar a democracia sem pensar a coerção, o autor trabalha com a definição de Ian Shapiro, de que a "democracia é mais bem pensada como meio de administrar as relações de poder a fim de que a dominação seja minimizada" (p. 27). Assim, uma coisa remete à outra: a dominação leva à coerção física que, por sua vez, não pode ser imaginada sem que se considerem as Forças Armadas e as polícias. Para Zaverucha, a noção de democracia tutelada, emprestada de Adam Przeworski, parece encaixar-se bem à realidade brasileira: "Embora a competição eleitoral no Brasil venha se aprimorando, as Forças Armadas continuam a constranger os líderes políticos quando eles decidem ameaçar os interesses castrenses" (p. 36). Exemplos não faltariam, a julgar pelo que retira do noticiário e expõe nas quase trezentas páginas de FHC, Forças Armadas e policia: entre o autoritarismo e a democracia (1999-2002).
De acordo com a análise de Zaverucha, viveríamos hoje (e nos últimos vinte anos) em um regime híbrido, nos moldes pensados por Marina Ottaway, com características democráticas e autoritárias coexistindo:

O caso brasileiro aproxima-se mais de uma semidemocracia pois não encontro um projeto deliberado das elites políticas de manterem esse hibridismo indefinidamente. Como é o caso do semi-autoritarismo. O hibridismo existente é muito mais fruto das circunstâncias políticas existentes (pp. 39-40).

O autor não disfarça que se sente pouco à vontade com as principais teorias de democracia. Acredita haver um vazio conceitual e que, assim como as teorias que tratam da democratização, elas também não são persuasivas. Prefere observar, portanto, os fatos e interpretá-los tendo como referência "o horizonte meta político-eleitoral que lhes dá sentido e valor" (p. 22). Seu admissível desconforto é revelador daquele que talvez constitua o aspecto mais frágil de sua obra, evidenciado na escolha de Joseph Schumpeter como principal interlocutor. Embora reconheça a importância formal da competição eleitoral, Zaverucha avalia tal critério insuficiente para que se possa considerar determinado país democrático e observa, desapontado, que uma suposta "vitória da concepção schumpeteriana atingiu os estudos sobre a redemocratização no Brasil". Parece ressentir-se das análises sobre sistema eleitoral e partidário, das pesquisas que tratam das relações Executivo-Legislativo, enfim, de tudo o que classifica como "uma agenda política atemporal: o que se estuda em um país como, digamos, a Dinamarca, seria similar ao que se debate no Brasil" (p. 28).

Para além de considerar atemporal - e possivelmente excludente -, o que no mais das vezes costuma revelar tensões e equilíbrios políticos bastante indicativos do momento em que determinada realidade é capturada (e cuja compreensão certamente não prescinde de memória e história), a opção por dialogar prioritariamente com Schumpeter não contribui para o entendimento do objeto central de sua obra (notadamente a relação entre democracia e controle civil sobre os militares). Pelo contrário. Confunde o leitor que, sem 
entender o porquê da escolha, se vê no meio de um diálogo estéril, protagonizado por um autor visivelmente incomodado com a relação schumpeteriana entre democracia e competição eleitoral, mas que, ao trabalhar sua questão, a ele se remete com freqüência. Tal escolha se mostra ainda menos compreensível quando se observa a preocupação de Zaverucha em não falar apenas com seus pares, distanciando-se da linguagem acadêmica e buscando o leitor comum, mesmo que de forma duvidosa, como ao escrever: "Qual a importância da competição eleitoral para o miserável coletor de mel, para o pescador de lagosta e para o emigrante brasileiro?" (p. 21).

Se a obra sofre com o que parece ser uma escolha contraproducente na interlocução teórica, a infinidade de exemplos concretos surpreende até mesmo quem tem alguma familiaridade com o tema. Embora trabalhe com o recorte 1999-2002, a persistência do legado autoritário obriga o autor a voltar, algumas vezes, aos anos de 1960, 1970 e 1980, para buscar as origens de determinada prática legal. Nessa tarefa, o próprio Zaverucha mal consegue disfarçar seu assombro ao lembrar que, em pleno século XXI, permanecem em vigor a Lei de Segurança Nacional, os Códigos Penal e Processual Militar etc. Afinal, como ele mesmo observa, o Congresso Nacional já emendou a Constituição quase meia centena de vezes, mas "ainda não fez mudanças significativas nas relações civis-militares" (p. 49). Isso depois de a Assembléia Constituinte e, conseqüentemente, a Constituição terem tratado de maneira nada progressista as relações entre civis e militares, mantendo "muitas prerrogativas não-democráticas" (p. 54), existentes no documento anterior ou mesmo adicionando novas. Assim, passados mais de vinte anos do fim do arbítrio, aponta ele, ainda não há, por exemplo, uma separação clara entre as funções das Forças Armadas e das polícias, que continuam a defender mais o Estado do que seus cidadãos.

Em relação ao segundo governo de FHC, foco propriamente dito de seu trabalho, os exemplos sistematizados por Zaverucha elevam o tom quase trágico de sua análise. Ao mesmo tempo em que lembra que o aprofundamento da democracia é incompatível com a militarização da segurança pública, o autor procura demonstrar que Fernando Henrique Cardoso teria contribuído sobremaneira para o aumento do poder militar. De acordo com Zaverucha, no segundo mandato de FHC manteve-se "a velha ótica do inimigo interno" - para ilustrar ele cita, entre outros, o caso de documentos secretos do Exército, revelados pela imprensa, que classificavam movimentos sociais como "forças adversas" e admitiam "arranhar direitos dos cidadãos" em nome da manutenção da lei e da ordem. A Casa Militar (que em setembro de 1999 se tornaria Gabinete de Segurança Institucional) passou a acumular a função de gerenciar crises envolvendo assuntos de segurança pública, e, apesar de declarações em contrário do próprio presidente, a Abin não prosseguiu subordinada à presidência da República, sendo transferida para a esfera do Ministério do Gabinete de Segurança Institucional. "Mesmo durante o regime militar quem dirigia o SNI, ou seja, a coleta de informações, não era quem tomava a decisão do que fazer com elas. No governo FHC, todavia, essas duas competências ficaram concentradas na figura de uma única pessoa: o general Alberto Cardoso" (pp. 164-165).

Outro exemplo do desmesurado poder militar estaria estampado, segundo Zaverucha, em seu orçamento: "Em um país com tantas carências sociais e de infra-estrutura como o Brasil, chama a atenção o fato de, entre 1995-2002, as Forças Armadas terem recebido o terceiro maior orçamento da União" (p. 93). No período analisado, seus gastos seriam maiores do que os relativos à Educação, ao Saneamento, à Habitação e ao Trabalho, perdendo apenas para a Previdência Social e Saúde (no que diz respeito, de acordo com o autor, não apenas à dotação orçamentária inicial, mas também à dotação suplementar e sua capacidade executória). Zaverucha ressalva, contudo, o fato de a maior parte dos gastos militares ter sido usada para cobrir a folha de pagamentos, sempre crescente, especialmente em relação aos aposentados. Os gastos com investimentos e custeio teriam caído, reforçando a imagem de penúria das instituições militares perante a opinião pública. A criação do Ministério da Defesa segue o mesmo raciocínio. Zaverucha acredita que sua institucionalização atendeu a fins instrumentais ("uma clara manobra política para favorecer a candidatura do Brasil a um assento no Conselho de Segurança da ONU") e que a pasta não foi 
criada para contribuir com a submissão dos militares ao controle democrático civil (p. 215). Em síntese, depois de usar dados do instituto Latinobarómetro para indicar que o Brasil, entre os pesquisados, "é o país que apresenta o índice mais baixo de crença na democracia como melhor sistema de governo" (pp. 15-16), Zaverucha parece convicto de que as Forças Armadas pairam sobre as instituições democráticas como sombras ameaçadoras - tal como sugere a capa de sua obra.

Detentores de tanto poder, por que então os militares não tentaram voltar a ocupá-lo efetivamente? Porque tal medida extrema não se fez necessária, arrisca Zaverucha, logo no início do livro: "se não houve prontidão militar, deveu-se ao fato de os civis cederem às pressões militares quando estas ameaçam acionar os dispositivos de uma prontidão militar. E não por os militares serem obedientes ao poder civil" (p. 15).

Tal afirmação, como quase tudo que está na obra, causa desconforto, e Zaverucha sabe que rema contra a maré. Isso não importa tanto, ou melhor, é possível suportar asserções como essa, à medida que se consegue perceber aquele que, junto com o exercício da memória, constitui o principal mérito do livro: manter em debate o papel das Forças Armadas em uma sociedade democrática. Como não esquece Zaverucha, para além do que seria democrático imaginar, os militares continuam extremamente presentes em muitas outras esferas da vida nacional, tomando parte, inclusive, em importantes atividades econômicas a crise aérea e seus desdobramentos constituiriam o exemplo mais contundente. A julgar pelas informações que apresenta, lamenta-se, contudo, que o autor não tenha aprofundado o quadro comparativo que esboça com Portugal, Guatemala, Peru e outros países da América do Sul. O que não se pode tolerar, entretanto, é que por mais arraigada que seja a influência militar, e por mais disseminado que seja o legado de arbítrio, alguém ainda trate as violações ocorridas no pós-64 como "supostos" abusos de direitos humanos (p. 59) ou que classifique a criminosa posição das Forças Armadas, de até hoje não prestar contas dos desaparecimentos e mortes ocorridos durante o regime militar, de "imbróglio político" (p. 197).

\author{
GLENDA MEZAROBBA é doutoranda no \\ Departamento de Ciência Política da USP e \\ autora de $U m$ acerto de contas com ofuturo: \\ a anistia e suas conseqüiências - um estudo \\ do caso brasileiro (Humanitas/Fapesp, \\ 2006). E-mail: gmez@uol.com.br.
}

